\title{
Synchrony of Clonal Cell Proliferation and Contiguity of Clonally Related Cells: Production of Mosaicism in the Ventricular Zone of Developing Mouse Neocortex
}

\author{
Li Cai, ${ }^{1,2}$ Nancy L. Hayes, ${ }^{1}$ and Richard S. Nowakowski ${ }^{1,2}$ \\ ${ }^{1}$ Department of Neuroscience and Cell Biology, and 2Physiology and Neurobiology Graduate Program, \\ Rutgers University and University of Medicine and Dentistry of New Jersey-Robert Wood Johnson Medical School, \\ Piscataway, New Jersey 08854
}

\begin{abstract}
We have analyzed clonal cell proliferation in the ventricular zone (VZ) of the early developing mouse neocortex with a replicationincompetent retrovirus encoding human placental alkaline phosphatase (AP). The retrovirus was injected into the lateral ventricles on embryonic day 11 (E11), i.e., at the onset of neuronogenesis. Three days postinjection, on E14, a total of 259 AP-labeled clones of various sizes were found in 7 fetal brains. There are approximately 7 cell cycles between E11 and E14 (Takahashi et al., 1995a), and there is a 1-2 cell cycle delay between retroviral injection and the production of a retrovirally labeled "founder" cell; thus, we estimate that the "age" of the clones was about 5-6 cell cycles. Almost one-half of the clones $(48.3 \%)$ identified were pure proliferating clones containing cells only in the VZ. Another $18.5 \%$ contained both proliferating and postproliferative cells, and $33.2 \%$ contained only postproliferative cells. It was striking that over $90 \%$ of the clonally related proliferating cells occurred in clusters of two or more
\end{abstract}

apparently contiguous cells, and about $73 \%$ of the proliferating cells occurred in clusters of three or more cells. Regardless of the number of cells in the clone, these clusters were tightly packed and confined to a single level of the VZ. This clustering of proliferating cells indicates that clonally related cells maintain neighbor-neighbor relationships as they undergo interkinetic nuclear migration and progress through several cell cycles, and, as a result, the ventricular zone is a mosaic of small clusters of clonally related and synchronously cycling cells. In addition, cells in the intermediate zone and the cortical plate were also frequently clustered, indicating that they became postproliferative at a similar time and that the output of the VZ is influenced by its mosaic structure.

Key words: neuronogenesis; cell cycle; pseudostratified ventricular epithelium; interkinetic nuclear migration; retrovirus vector; clonal lineage
During the early development of the mammalian cerebral cortex, virtually all cell proliferation occurs in a pseudostratified ventricular epithelium (PVE) that is approximately coextensive with the ventricular zone (VZ) lining the lateral ventricles (for references see Boulder Committee, 1970; Caviness et al., 1995; Takahashi et al., 1995a). Sauer (1935) suggested that the nuclei of proliferating cells in the developing CNS move "to-and-fro" such that they are located adjacent to the ventricular surface during $M$ phase and in the abventricular portion of the proliferative zone during other phases of the cell cycle. In the late 1950 s, experiments exploiting the then newly synthesized tracer tritiated thymidine confirmed that nuclei in $\mathrm{S}$ phase are indeed located in the outer half of the proliferative zone (Sauer and Walker, 1959; Sidman et al., 1959; Sidman, 1970). Subsequently, such nuclear movements were shown to be a feature of all proliferating columnar epithelia (Leblond, 1964). Most recently, it was demonstrated that the change in direction of movement of the nuclei corresponds to the phase of the cell cycle, with reversals occurring abventricularly at the $\mathrm{G}_{1}-\mathrm{S}$ transition (Takahashi et al., 1994), as well as adventricu-

\footnotetext{
Received Aug. 5, 1996; revised Dec. 17, 1996; accepted Dec. 20, 1996.

This work was supported by National Institutes of Health Grants NS28061 and NS33443 and NASA Grant NAG2-950.

Correspondence should be addressed to Dr. Richard S. Nowakowski, Department of Neuroscience and Cell Biology, UMDNJ-Robert Wood Johnson Medical School, Piscataway, NJ 08854.

Copyright (C) 1997 Society for Neuroscience $0270-6474 / 97 / 172088-13 \$ 05.00 / 0$
}

larly at the $M-G_{1}$ transition. Postproliferative cells migrate outward from the VZ along radial glial fibers across an intermediate zone (IZ) to form the developing cortical plate (CP) in an inside-out pattern, such that successively later born neurons occupy progressively more superficial laminae (Rakic, 1972, 1988).

Recently, we have determined that during neocortical development between E11 and E14, the variation of the cell cycle length $\left(\mathrm{T}_{\mathrm{C}}\right)$ is $< \pm 8 \%$ of the mean (Cai et al., 1993, 1995, 1997). The narrow range of $T_{C}$ indicates that there is considerable homogeneity in the rate of passage of proliferating cells through the cell cycle, and also that $98-99 \%$ of the proliferating population has a similar cell cycle time. As a consequence of this homogeneity in $T_{C}$, two daughter cells from a single symmetrical mitosis will progress through the cell cycle at a similar rate. One cell cycle later, a second symmetrical mitosis would produce four granddaughter cells that will also progress through the cell cycle at a similar rate. If this were to continue for several cycles, clusters of clonally related cells would be expected to arise in the VZ.

To test this hypothesis, we studied the behavior of the proliferating population, the patterns of interkinetic nuclear migration, and the physical relationships between/among clonally related proliferating cells, by injecting a replicationincompetent retrovirus into the lateral ventricles of E11 mouse brain, i.e., close to the onset of neuronogenesis. A marker gene from the retrovirus (i.e., human placental alkaline phospha- 
tase, AP) is incorporated into the genomic DNA of dividing cells and remains in one of the two daughter cells (Sanes et al., 1986; Cepko, 1988; Hajihosseini et al., 1993), which becomes a founder cell for clonal expansion. All of the descendants of the founder cell express histochemically detectable marker, making it possible to tag and follow the ontogeny of individual clones. For this analysis we focused on the members of the clone that were still proliferating $3 \mathrm{~d}$ after the exposure to the retrovirus; from previous measurements of the cell cycle $3 \mathrm{~d}$ is sufficient for $5 \pm 1$ cell cycles (Takahashi et al., 1995a).

\section{MATERIALS AND METHODS}

Retrovirus vectors. The DAP retrovirus vector, a replication-incompetent retrovirus encoding AP, was used for this study. Previous studies have characterized the DAP retrovirus vector as a useful histochemical marker and have found that AP-labeled cortical progenitor cells demonstrate proliferative behavior indistinguishable from that of normal progenitor cells (Fields-Berry et al., 1992; Halliday and Cepko, 1992; Reid et al., 1995). We found no evidence to contradict this general conclusion. Construction and production of the DAP retrovirus has been documented previously (Fields-Berry et al., 1992). DAP retrovirus-producing cells were purchased from American Type Culture Collection (CRL1949; Fields-Berry et al., 1992) and grown in culture to confluence; retroviral supernatant was collected, filtered, concentrated by overnight centrifugation, aliquoted, and stored at $-80^{\circ} \mathrm{C}$ (Cepko, 1990). The titer of the concentrated DAP retrovirus stock, determined according to a published procedure (Cepko, 1990), was $10^{7}$ colony forming units (CFU)/ml. A few experiments were also performed with DAP retrovirus that was the generous gift of Chris Walsh (Harvard Medical School).

Animals and surgical procedures. Timed-pregnant CD-1 mice were purchased from Charles River Laboratories (Wilmington, MA), and maintained on a $12 \mathrm{hr} / 12 \mathrm{hr}$ (7:00 A.M. to 7:00 P.M.) light/dark schedule from the time of arrival until the time of the experiment. Pregnancies were timed from the day at which a vaginal plug was detected, which was designated as E0. By this convention, birth would normally occur on E19.

On E11, pregnant mice were anesthetized with Avertin $(0.02 \mathrm{ml} / \mathrm{gm}$ body weight, i.p.) before performing a laparotomy. The uterine horns were exposed, and a fiber optic light source was used to transilluminate each uterine swelling so that the orientation of the fetal head could be established without incising the uterus. Once the ventricles were visualized, the uterine membranes and fetal skull were penetrated with a glass micropipette (PCR Micropipets, Drummond Scientific Company, Broomall, PA). Approximately $0.5 \mu \mathrm{l}$ of a solution containing $\sim 10^{7}$ $\mathrm{CFU} / \mathrm{ml}$ DAP retrovirus vector, $0.05 \mathrm{mg} / \mathrm{ml}$ polybrene, and $0.025 \%$ fast green dye was pressure injected through the uterine wall directly into the fetal cerebral ventricles. The fast green dye allowed verification of the placement of the solution into the lateral ventricles. When injections were complete, the abdominal incision was closed, and the dam was kept warm until awake and normal.

Tissue processing and histochemistry. On E14, $3 \mathrm{~d}$ after the intraventricular injections, the dams were deeply anesthetized with $4 \%$ chloral hydrate. The injected embryos were quickly removed by hysterotomy and decapitated, and the whole heads were fixed overnight by immersion in $4 \%$ paraformaldehyde in $0.1 \mathrm{~m}$ phosphate buffer, $\mathrm{pH}$ 7.4. The brains were then removed and rinsed in PBS, transferred to $10 \%$ sucrose in PBS until they sank, and then transferred to $30 \%$ sucrose until they sank again (about $12 \mathrm{hr}$ ). The brains were surrounded with OCT compound (Miles Laboratories, Inc., Elkhart, IN) and frozen on a cryostat (Reichert-Jung 2800 Frigocut N). Serial sections of 30-40 $\mu \mathrm{m}$ thickness were cut, mounted on slides coated with 3-aminopropyltriethoxy-silane (Rentrop et al., 1986), and air dried overnight. Slides were processed for AP activity according to a modification of a procedure described previously (Fields-Berry et al., 1992). Sections were fixed for $10 \mathrm{~min}$ in $4 \%$ paraformaldehyde, rinsed in PBS, and incubated in a $65^{\circ} \mathrm{C}$ bath for $30-45$ min to destroy endogenous AP activity. After removal from the bath, the slides were placed in AP buffer (100 mM Tris- $\left.\mathrm{HCl}, \mathrm{pH} 9.5,100 \mathrm{~mm} \mathrm{NaCl}, 5-50 \mathrm{~mm} \mathrm{MgCl}_{2}\right)$ for $10 \mathrm{~min}$, incubated in the dark for $8 \mathrm{hr}$ to overnight at room temperature in $0.1 \mathrm{mg} / \mathrm{ml} \mathrm{X-phosphate,} 1 \mathrm{mg} / \mathrm{ml}$ Nitro Blue Tetrazolium, $0.24 \mathrm{mg} / \mathrm{ml}$ levamisole (L[-]-2,3,5,6-tetrahydro-6-phenylimidazo [2,1-b] thiazole hydrochloride) in AP buffer (BCIP/NBT Phosphatase Substrate Sys- tem, Kirkegaard \& Perry Laboratories, Gaithersburg, MD), washed with PBS, dehydrated through graded alcohols, cleared in histoclear (National Diagnostics, Atlanta, GA), and coverslipped with DPX (BDH Laboratory Supplies, Poole, England).

Clonal analysis. Tissue sections were examined microscopically, and cell morphologies and positions within the neocortex were recorded photographically and on drawings made with the aid of a camera lucida. A clone was defined as an isolated cluster of AP-labeled cells (with nuclei in the VZ and/or the more superficial strata) arranged into a radially aligned cylinder of $<150 \mu \mathrm{m}$ in diameter. A diameter of 150 $\mu \mathrm{m}$ was derived from a "random walk" computer simulation, which determined that $95 \%$ of cells derived from a single founder cell undergoing random walk movements in the $\mathrm{VZ}$ at a rate of $75 \mu \mathrm{m} / 8 \mathrm{hr}$ (Fishell et al., 1993) for $3 \mathrm{~d}$ (E11 to E14) would fall into a $150 \mu \mathrm{m}$ diameter circle. Clone size was determined by counting the number of labeled cells in each cortical stratum in serial sections through each clone.

Clone age. We estimate that the number of cell cycles elapsed during the survival time of the experiment is $5 \pm 1$. We have shown previously that the range of $T_{C}$ for VZ cells is limited (Cai et al., 1993, 1997). This means that the "age" range of the clones produced is also relatively limited. For the 3 d survival period (i.e., E11 through E14), there are about seven cell cycles in the dorsomedial neocortex (Takahashi et al., 1995b) and six cell cycles in the ventrolateral neocortex (S. Miyama, T. Takahashi, R. Nowakowski, and V. Calviness J., unpublished observations). Because the retrovirus has a short half-life [about $4 \mathrm{hr}$ at $37^{\circ} \mathrm{C}$ (Cepko, 1990)], infection of the proliferating progenitor cells must occur shortly after the time of injection. However, the establishment of a clone will not occur until the viral genome is stably inserted into the genome of a neuronal progenitor cell. This occurs 1-2 cell cycles after the retroviral injection and results in a single retrovirally labeled founder cell at the beginning of $\mathrm{G}_{1}$. Thus, only 5-6 integer cell cycles in the dorsomedial neocortex and 4-5 integer cell cycles in the lateral neocortex are available for clonal expansion. Because the area we studied includes both the dorsomedial and ventrolateral neocortex, the age for the clones may vary from 6 cell cycles in the dorsomedial neocortex to 4 cell cycles in the ventrolateral neocortex. The fact that the largest clone we found contained 24 cells confirms our estimate of $4-6$ cell cycles for clonal expansion for this experiment. This is because the maximum size for a clone that expands for 4 cell cycles is only 16 cells.

Nomenclature. The classification of the AP-labeled cells as proliferative or postproliferative was based on their position in the cortical strata. Thus, cells occupying the VZ (VZ cells) were classified as proliferative. Cells occupying the IZ or $\mathrm{CP}$ (IZ cells or CP cells) were classified as postproliferative. Within the $\mathrm{VZ}$, cells occupying the inner half were considered to be in $G_{2}$, M, or early $G_{1}$, whereas cells occupying the outer half were considered to be in late $G_{1}$ or $S$.

\section{RESULTS}

\section{Distribution, number, and size of clones}

Three days after injection of retrovirus into the lateral ventricles at E11, retrovirally encoded AP produced intense purple labeling of cell bodies and sometimes also of cellular processes. A total of 259 clones, consisting of a total of 966 AP-labeled cells, was identified and analyzed in 7 fetal brains, which is an average of 37 clones per brain, or 18-19 clones per hemisphere. Clones were found almost evenly distributed throughout the neocortex, and most labeled clones (well over 95\%) identified were less than 50 $\mu \mathrm{m}$ in diameter, i.e., much smaller than the $150 \mu \mathrm{m}$ in diameter criterion established by a random walk model (see Materials and Methods), and were well isolated from other labeled clones by a distance greater than $300 \mu \mathrm{m}$. AP-labeled cells were found in all of the strata of the developing cortex, i.e., the VZ, IZ, and CP. The number of cells/clone and their distribution in each cortical stratum are listed in Table 1, and a frequency histogram illustrating the individual clone sizes is shown in Figure 1. The mean clone size was 3.7 cells/clone (as indicated by the arrow in Fig. 1). A detailed analysis of the comparison of experimentally determined 


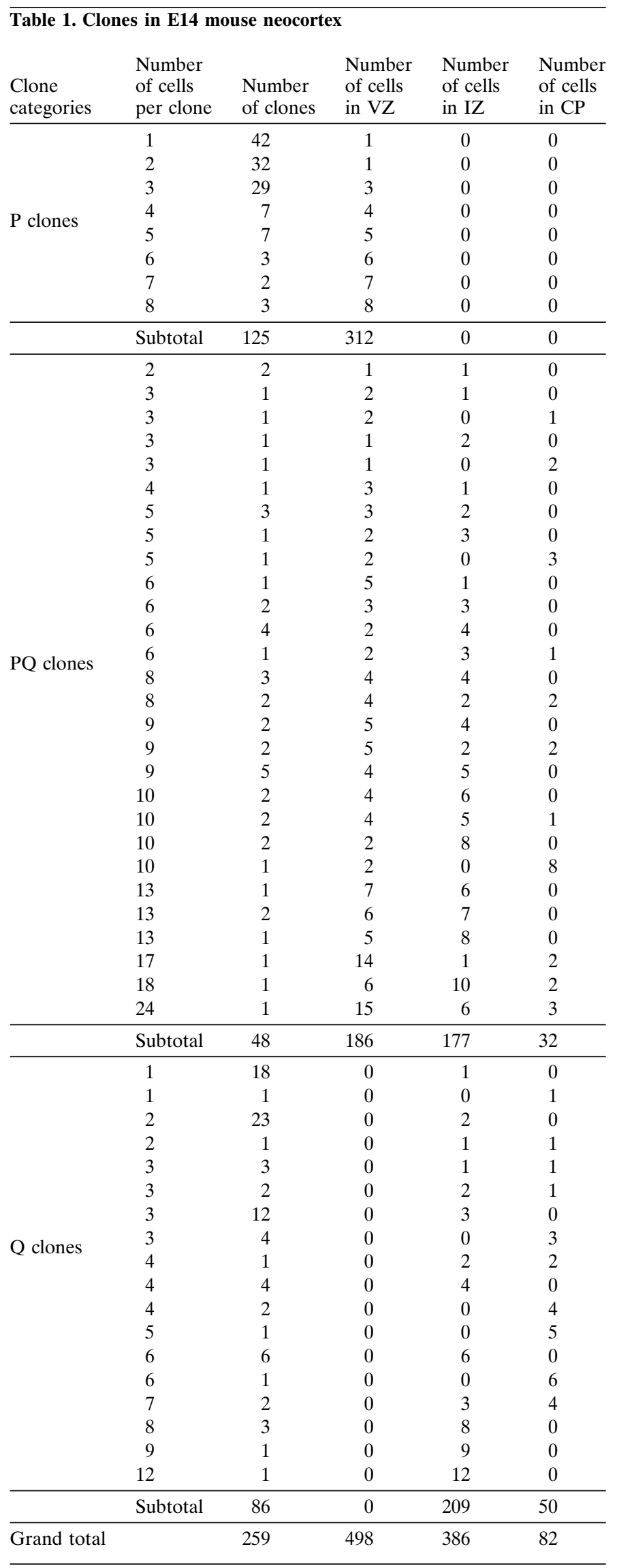

clone sizes and the predictions of a mathematical model is presented elsewhere (Cai et al., 1996). Thus, this analysis will focus on the qualitative, rather than the quantitative, characteristics of the clones.

On the basis of the distribution of cells in the developing neocortical strata, the clones were classified into three categories: P clones, Q clones, and PQ clones. A P clone was defined as a clone with one or more VZ cells, and no IZ cells or $\mathrm{CP}$ cells (Fig. $2 A, B$ ). A $\mathrm{Q}$ clone was defined as a clone with no $\mathrm{VZ}$ cells but one or more IZ cells and/or CP cells (Fig. 2C,D). A PQ clone was defined as a clone which had both one or more VZ cells and any number of IZ cells and/or CP cells (Fig. $2 E, F)$. $\mathrm{P}$ clones are, therefore, pure proliferative clones, $\mathrm{Q}$ clones are pure postproliferative clones, and PQ clones are clones with a mixture of both proliferating cells and postproliferative cells. Of the 259 clones found, $48.3 \%$ were P clones, $33.2 \%$ were Q clones, and $18.5 \%$ were PQ clones.

For this study, we have focused our attention on only those clones that contain proliferating cells, i.e., on P clones and PQ clones. For the most part, we have focused on the proliferative component of the $\mathrm{P}$ clones and PQ clones, i.e., the VZ cells that we assume are part of the PVE (Takahashi et al., 1995a). This is because the "history" of VZ cells is known; they have continued to proliferate for the entire duration of the experiment, i.e., 4-6 cell cycles. Thus, the complete history of $\mathrm{P}$ clones and the partial history of PQ clones are known. No specific information is known for the $\mathrm{Q}$ clones with regard to when the IZ cells and CP cells left the VZ, although they must have had sufficient time to migrate to the positions they occupied at the time of sacrifice. A histogram of the number of $\mathrm{VZ}$ cells per clone (Fig. $1 B$ ) shows that many of the clones contained only a few VZ cells, including $27 \%$ of the clones that contained only a single VZ cell. However, of the $73 \%$ of the clones that contained two or more VZ cells, only $48 \%$ contained three or more VZ cells (Fig. $1 B$ ). In terms of the composition of the $\mathrm{VZ}$ at E14, however, it is important to consider not only the number of clones found (Fig. $1 B$ ) but also the number of cells found and the proportional representation of VZ cells within each clone (Fig. $1 C$ ). The pie chart in Figure $1 C$ shows that of the total number of AP-labeled cells in the VZ (i.e., 498 cells), only $9 \%$ of them were in clones that contained only a single VZ cell, and the vast majority of the AP-labeled cells $(91 \%)$ were part of clones containing at least one other VZ cell. Almost three-fourths of the VZ cells (73\%) were part of clones containing at least two other VZ cells, and over one-half $(52 \%)$ were part of clones containing at least three other VZ cells. It is interesting to note in particular that even though the largest clones (i.e., those containing 5 or more VZ cells) comprised only $16 \%$ of the total clone population (Fig. $1 B)$, this group of large clones contains over $35 \%$ of the AP-labeled VZ cells (Fig. 1C). Thus, most of the cells of the $\mathrm{VZ}$ are part of clones that contain multiple $\mathrm{VZ}$ cells.

\section{P clones}

A total of $125 \mathrm{P}$ clones was found. Cells of P clones had large, round nuclei, abundant cytoplasm, and usually no visible processes (Figs. $2 A, B, 4$ ). The sizes of $\mathrm{P}$ clones ranged from one to eight cells. The mean size was 2.5 cells/clone.

\section{Uniform distribution of the one-cell P clones}

About one-third (33.6\%) of the P clones (42 of 125) had only one cell. The positions of the one-cell $\mathrm{P}$ clones in the thickness of the 

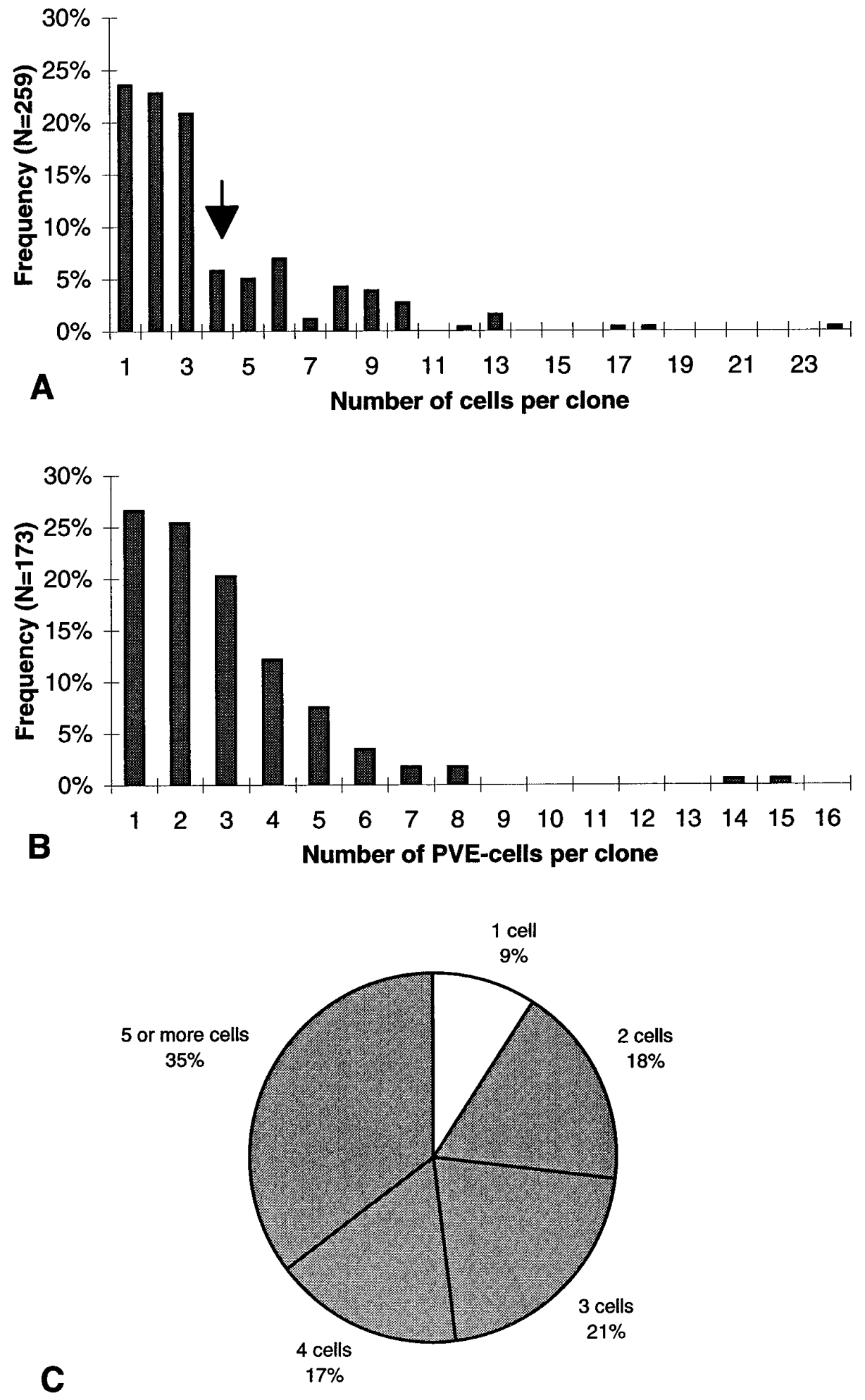

Figure 1. Frequency histograms showing the distribution of cells and clones found in the mouse neocortex at E14, $3 \mathrm{~d}$ after injections of DAP retrovirus at E11. $A$, The number of clones as a function of clone size is plotted as a percentage of all 259 AP-labeled clones. A majority of clones were small, containing only 1-3 cells, and only a small proportion of clones were large, containing $>11$ cells. The mean size of the clones (3.7 cells/clone) is indicated by an arrow. $B$, The number of VZ cells (proliferating cells) per clone is plotted as a percentage of the 173 clones that contained VZ cells. The largest cluster in the VZ contains 15 cells as shown at the right. $C$, The cellular composition of the VZ at E14 in terms of the percentage of cells residing in clones containing only a single $\mathrm{VZ}$ cell (white wedge) versus the percentage of cells residing in clones containing 2 or more cells ( gray wedges). The percentages along the perimeter of the pie chart indicate the percentage of APlabeled VZ cells found in clones containing 1,2, 3 , 4, and 5 or more VZ cells. This chart shows that only $\sim 9 \%$ of the total number of APlabeled VZ cells (498) belonged to clones that contained only a single $\mathrm{VZ}$ cell and that a vast majority of the AP-labeled VZ cells $(91 \%)$ were from clones that contained multiple cells clustered in the VZ.
$\mathrm{VZ}$ were measured and plotted as a function of VZ thickness as measured in deciles (Fig. 3). The distribution of the one-cell $\mathrm{P}$ clones in the $\mathrm{VZ}$ was found to be approximately uniform in that they were located at all levels of the VZ with approximately equal likelihood $\left(\chi^{2}=1.33 ; p=0.998\right)$. Figure 4 shows three one-cell $\mathrm{P}$ clones and their locations in the VZ, i.e., at the ventricular surface (Fig. $4 A$ ), in the middle of the VZ (Fig. $4 B$ ), and in the outer half of the VZ (Fig. $4 C$ ). Because the location of cells in the
VZ is correlated with the phase of the cell cycle (Sauer, 1935; Takahashi et al., 1994), a uniform distribution of one-cell P clones through the thickness of the VZ means that these clones were also uniformly distributed in the cell cycle at the time of sacrifice. Because cell cycle lengths are relatively homogeneous (Cai et al., 1993, 1997) cells are equally likely to be infected by the DAP retrovirus vector regardless of the phase of the cell cycle that they are in at the time of infection. 

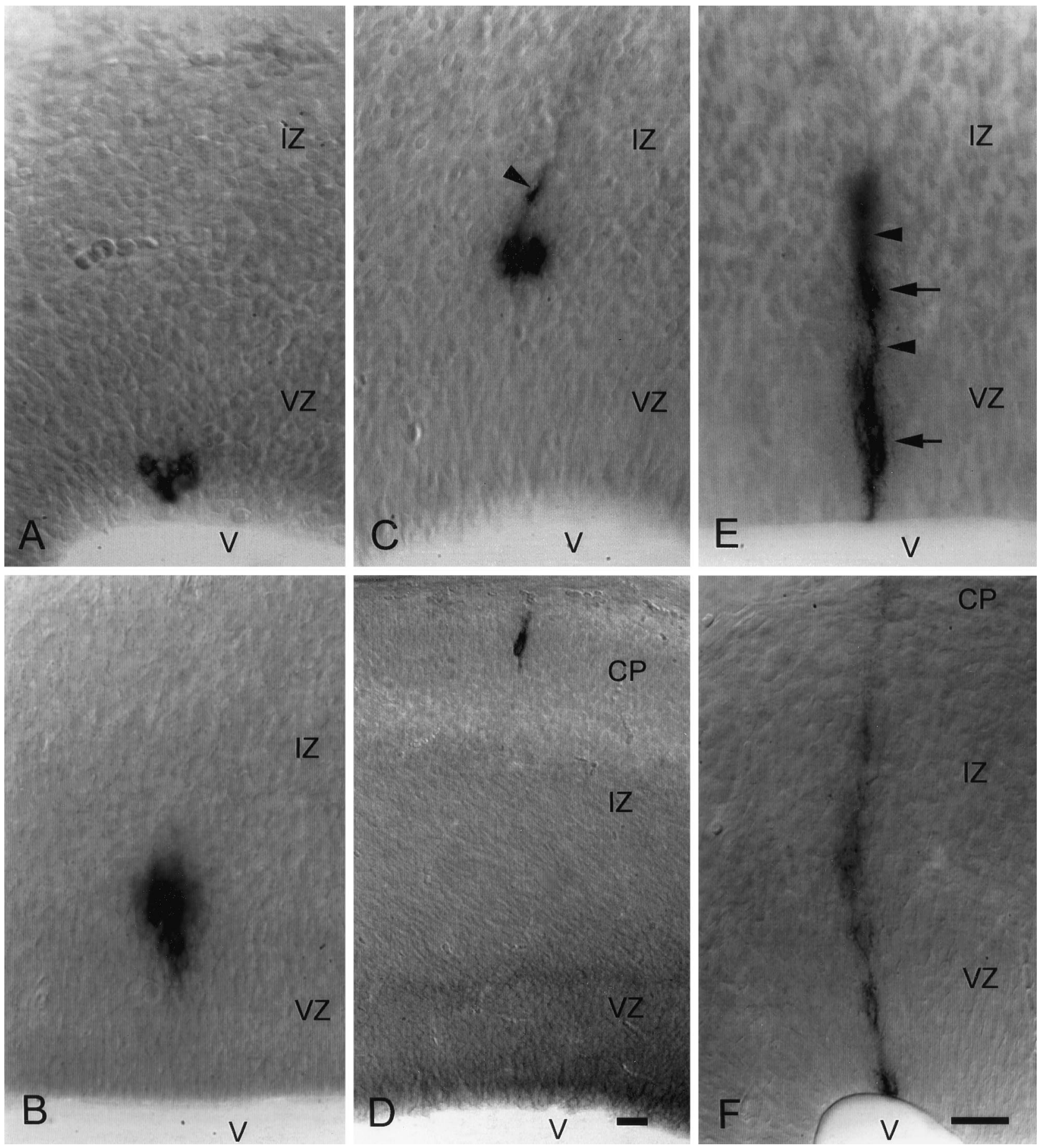

Figure 2. Examples of AP-labeled clones in mouse neocortex at E14, $3 \mathrm{~d}$ after DAP retrovirus injection at E11. $A, B, \mathrm{P}$ clones in which all AP-labeled cells are restricted to the VZ. The clone shown in $A$ has 8 cells that all seem to be in contact and are located near the ventricular surface. The clone shown in $B$ also has 8 cells in a tight cluster, but it is located in the outer one-half of the $\mathrm{VZ}$ near the VZ/IZ border. $C, D$, Q clones in which no cells were found in the VZ. The clone shown in $C$ consists of four cells in the middle of the IZ. One cell has a process that extends toward the CP (arrowhead). The clone shown in $D$ consists of one cell in the middle of the CP. No cells were found in the $\mathrm{VZ}$ and/or IZ or in the adjacent sections spanning $150 \mu \mathrm{m}$ in any direction. $E, F, \mathrm{PQ}$ clones that contain VZ cells and cells in at least one other stratum. The clone shown in $E$ contains $5 \mathrm{VZ}$ cells and $1 \mathrm{IZ}$ cell; no cells were found in the CP. The VZ cells (lower arrow) are tightly clustered in the middle of the VZ. The IZ cell (upper arrow) is located close to the VZ/IZ border, indicating that it recently left the VZ and started to migrate. A bundle of stained processes (arrowheads) can be seen extending radially from the ventricular surface to the middle of the IZ, and all of the cells of this clone are located along this radial bundle. The clone shown in $F$ contains cells in all three developing cortical strata, i.e., 5 VZ cells, 2 IZ cells, and $2 \mathrm{CP}$ cells. The cells are radially aligned at strikingly evenly spaced intervals, suggesting that they were produced at consecutive generations. Radial processes can be seen intertwining among the clusters of cells throughout the whole thickness of the developing cortical strata. The $2 \mathrm{VZ}$ cells are located side-by-side at the ventricular surface, as if they had recently completed anaphase. An additional VZ cell is in the middle of the VZ, as if it were in $\mathrm{G}_{1}$ or $\mathrm{G}_{2}$, and 2 more $\mathrm{VZ}$ cells are located in the outer one-third of the VZ close to the VZ/IZ border. The 2 IZ cells were clustered near the VZ cells at the border as if they had left the VZ only recently. The $2 \mathrm{CP}$ cells were also closely spaced, indicating that they also may be cousins that had left the VZ simultaneously but before the exit time of the $2 \mathrm{IZ}$ cells. $V$, Lateral ventricle. Scale bars, $20 \mu \mathrm{m}$. 


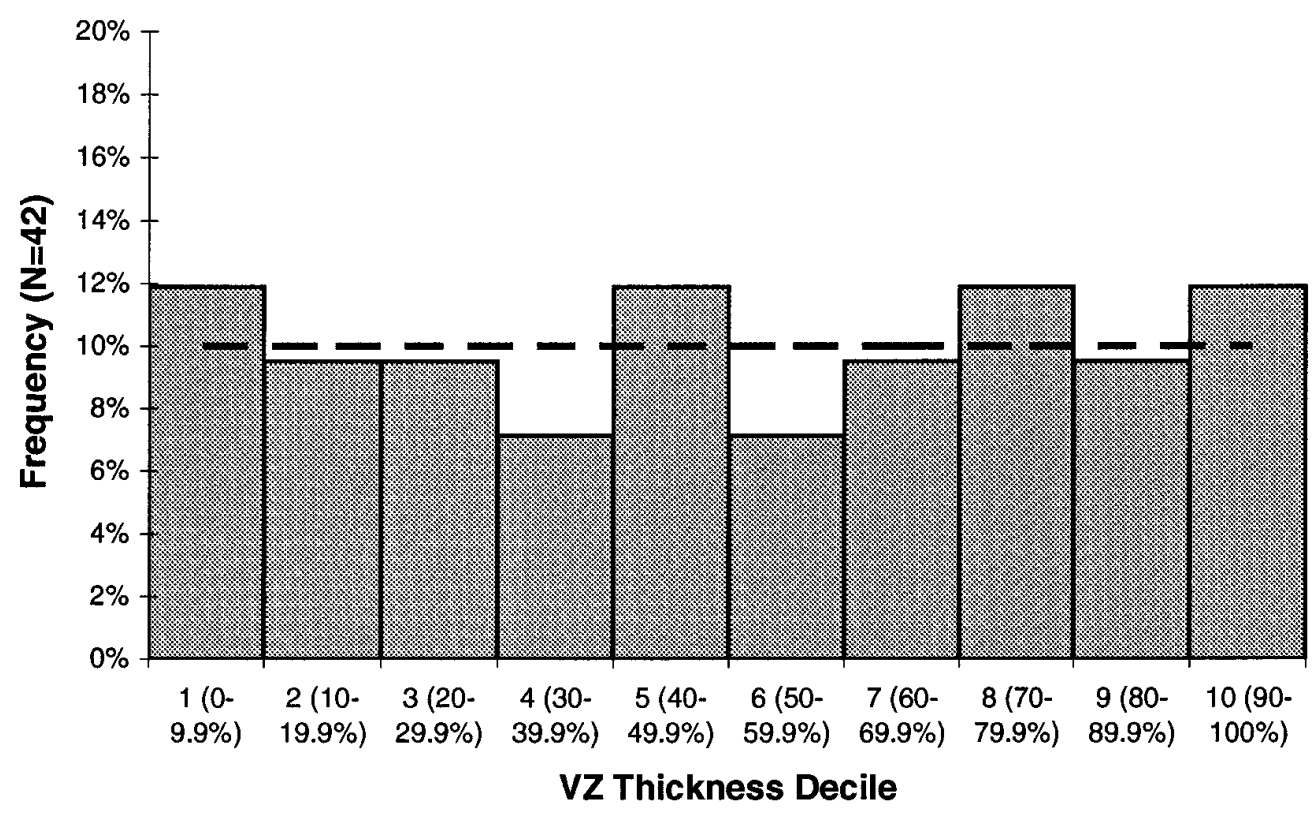

Figure 3. The distribution of one-cell $\mathrm{P}$ clones as a function of the thickness of the VZ obtained by dividing the VZ into 10 bins (deciles) parallel to the ventricular surface. For comparison, the dotted line shows the percentage of clones/bin if they were distributed uniformly in the VZ. The distribution of one-cell $\mathrm{P}$ clones is not significantly different from the uniform distribution $\left(\chi^{2}=1.33 ; p=0.998\right)$. This uniform distribution means that AP-labeled clones are also uniformly distributed in the cell cycle, which indicates that there is no preferred cell cycle phase for infection by the DAP retrovirus vector.

\section{Contiguously clustered VZ cells of the P clones}

About two-thirds (66.4\%) of the P clones (83 of 125) contained two or more cells. In virtually all (94\%) of the multicell P clones, there was little or no discernable space between the AP-labeled $\mathrm{VZ}$ cells, which formed tight clusters in the VZ. This pattern of association of the $\mathrm{VZ}$ cells in the $\mathrm{P}$ clones suggests a tendency to maximize the area of contact of cells in a clone.

In the two-cell $\mathrm{P}$ clones, the two $\mathrm{VZ}$ cells were always in apparent contact with no apparent space between the two cells (Fig. 4D-F). In more than one-half (19 of 32) of the two-cell $\mathrm{P}$ clones, the two nuclei were directly adjacent to each other, making contacts on their lateral surfaces (Fig. $4 D, E$ ); in the remaining two-cell $\mathrm{P}$ clones, the two VZ cells were in a supra/ subjacent relationship, making apparent contacts on their apical and basal surfaces (Fig. $4 F$ ). Two-cell $\mathrm{P}$ clones were found at all levels of the VZ, i.e., at the ventricular surface (Fig. $4 D$ ), in the middle of the VZ (Fig. $4 E$ ), or in the outer half of the VZ (Fig. 4F). Occasionally, the cellular processes of the APstained cells can be seen to extend radially across the thickness of the VZ (indicated by arrowhead in Fig. 4D). In the case of the two cell clones near the ventricular surface (Fig. $4 D$ ), the proximity of these two cells and their position close to the ventricular surface suggests that they are daughter cells from a recently completed mitotic division and only recently entered $\mathrm{G}_{1}$, but both laterally contacting two-cell clones and apical/ basal contacting two-cell clones were found throughout the VZ. This means that the two cell clones could be in any phase of the cell cycle. Our two-cell clone sample size $(n=32)$ was insufficient to determine whether there is any systematic relationship between angle of contact (e.g., horizontal vs vertical) and position in the VZ.

There were 29 three-cell $\mathrm{P}$ clones. Similar to the two-cell $\mathrm{P}$ clones, the three $\mathrm{VZ}$ cells were always tightly clustered and apparently touching, although physical arrangements varied. In $62 \%$ (18 of 29) of these clones, the three cells were arranged radially to form a column of cells in a subportion of the VZ (Fig. 4G,H), and in 38\% (11 of 29) of the clones, the three cells formed a triangle (Fig. $4 I$ ) or an inverted triangle (not illustrated). The various arrangements of three cell clones were found in both the inner and outer portions of the VZ.

Only $22 \mathrm{P}$ clones containing four or more cells were found. As for the smaller clones, the cells were almost always in apparent contact, and usually, cells in these clones were arranged in a fairly compact, almost spherical cluster with little or no discernible intercellular space (Fig. 2A,B). Exceptions to this spheroid organization were rare; for example, in one four-cell $\mathrm{P}$ clone, the four VZ cells formed a radial column beginning at the ventricular surface (not shown). As for the smaller clones, the large clones were found at all levels of the VZ. For example, the three largest $\mathrm{P}$ clones all contained eight cells. One of these had all eight cells clustered at the ventricular surface (Fig. 2A) and confined to an area extending about three cell diameters from the ventricular surface, indicating that members of this clone are in $G_{2}$ or early $G_{1}$. In another eight-cell clone (Fig. $2 B$ ), the eight cells are clustered in the outer one-third of the VZ, indicating that the members of this clone are in late $\mathrm{G}_{1}$ or $\mathrm{S}$. The third eight-cell $\mathrm{P}$ clone contained two clusters of VZ cells; it is a "radially split $\mathrm{P}$ clone" (Fig. $5 A$ ). It and other radially split clones are described in the following paragraph.

\section{Radially split P clones}

Only five multicell $\mathrm{P}$ clones were not confined to a single cluster of apparently contiguous cells. These five clones were split into two discrete clusters of cells with a clear radial separation between the two clusters and little or no separation of the cells in each cluster. The five radially split $\mathrm{P}$ clones were among the largest $\mathrm{P}$ clones. One contained eight cells, two contained seven cells, and two contained six cells. The two clusters of cells were usually not of the same size. Three of the five had the larger cluster (3-5 cells) located in the outer 

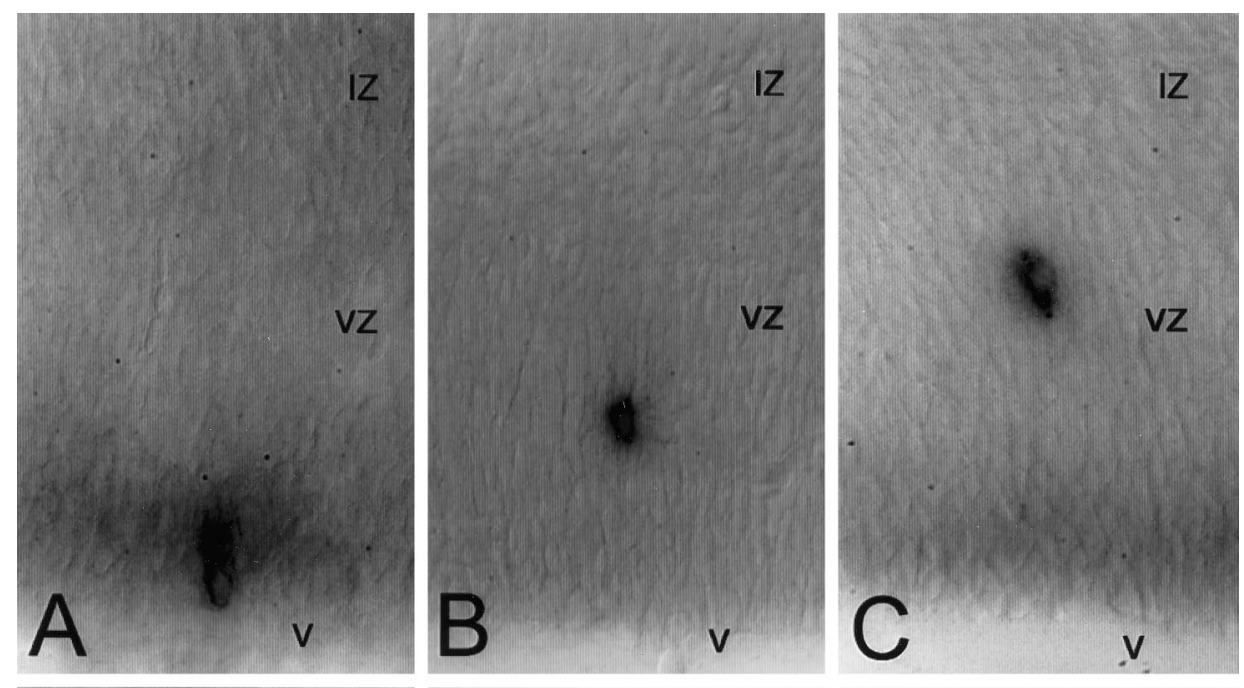

Figure 4. Examples of AP-labeled one-, two-, and three-cell $\mathrm{P}$ clones in the mouse neocortex at E14, $3 \mathrm{~d}$ after injections of DAP retrovirus vector at E11. $A-C$, One-cell $\mathrm{P}$ clones. In general, the cells in the VZ have a large, round nucleus, abundant cytoplasm, and usually no visible processes. The three clones shown are at different levels in the VZ, at the ventricular surface $(A)$, in the middle of the $\mathrm{VZ}(B)$, and in the outer one-half of the $\mathrm{VZ}$ near the VZ/IZ border $(C) . D-F$, Two-cell $\mathrm{P}$ clones. In two of the examples $(D, E)$, one at the ventricular surface $(D)$ and the other in the middle of the VZ $(E)$, the 2 cells seem to contact each other along one of their lateral borders. In the third example $(F)$, the $2 \mathrm{VZ}$ cells were in a supra/subjacent relationship and located in the outer one-half of the VZ, near the VZ/IZ border. $G-I$, Three-cell $\mathrm{P}$ clones. In all three examples, the 3 cells are clustered, but the physical arrangements vary: radially stacked at the ventricular surface $(G)$ or in the outer one-half of the $\mathrm{VZ}(H)$ or forming a triangular array $(I)$, in this case at the ventricular surface.
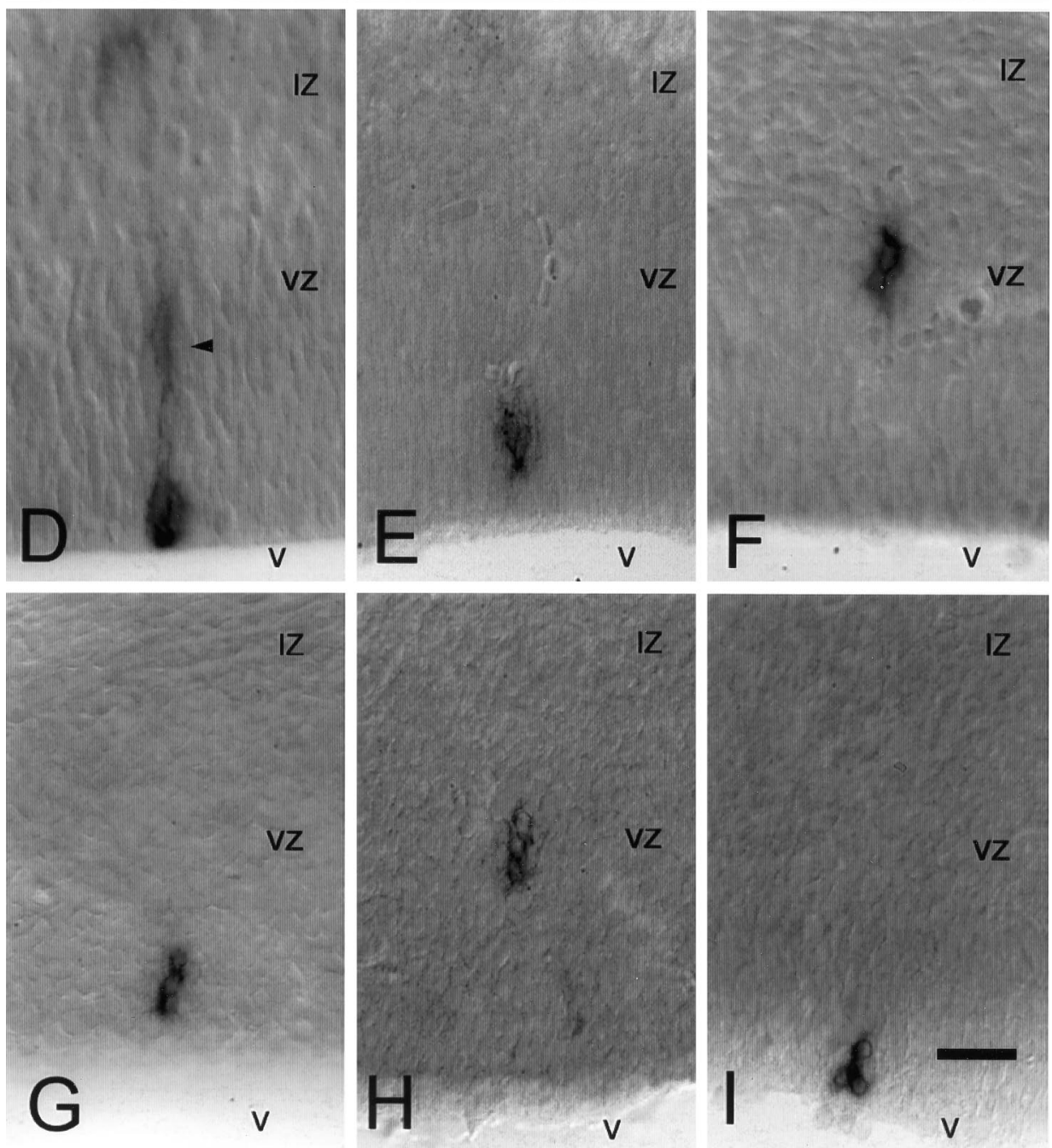

$V$, Lateral ventricle. Scale bar, $20 \mu \mathrm{m}$.

one-half of the VZ and the smaller (1-3 cells) at the ventricular surface. Two had the smaller cluster located in the outer one-third of the VZ and the larger cluster at the ventricular surface. The eightcell radially split $\mathrm{P}$ clone contained a smaller cluster of three cells in the outer one-third of the $\mathrm{VZ}$ and a larger cluster of five cells in the inner one-half of the VZ (Fig. $5 A$ ). The two clusters (as indicated by arrows in Fig. 5) were not compact spheroids as found in smaller $\mathrm{P}$ clones, but the tight packing and apparent contiguity of the cells was, nevertheless, similar to that of nonsplit P clones.

\section{PQ clones}

By definition, a PQ clone must contain two or more cells, i.e., at least 1 cell in the $\mathrm{VZ}$ and another cell in one of the more superficial strata. A total of $48 \mathrm{PQ}$ clones were found. They 

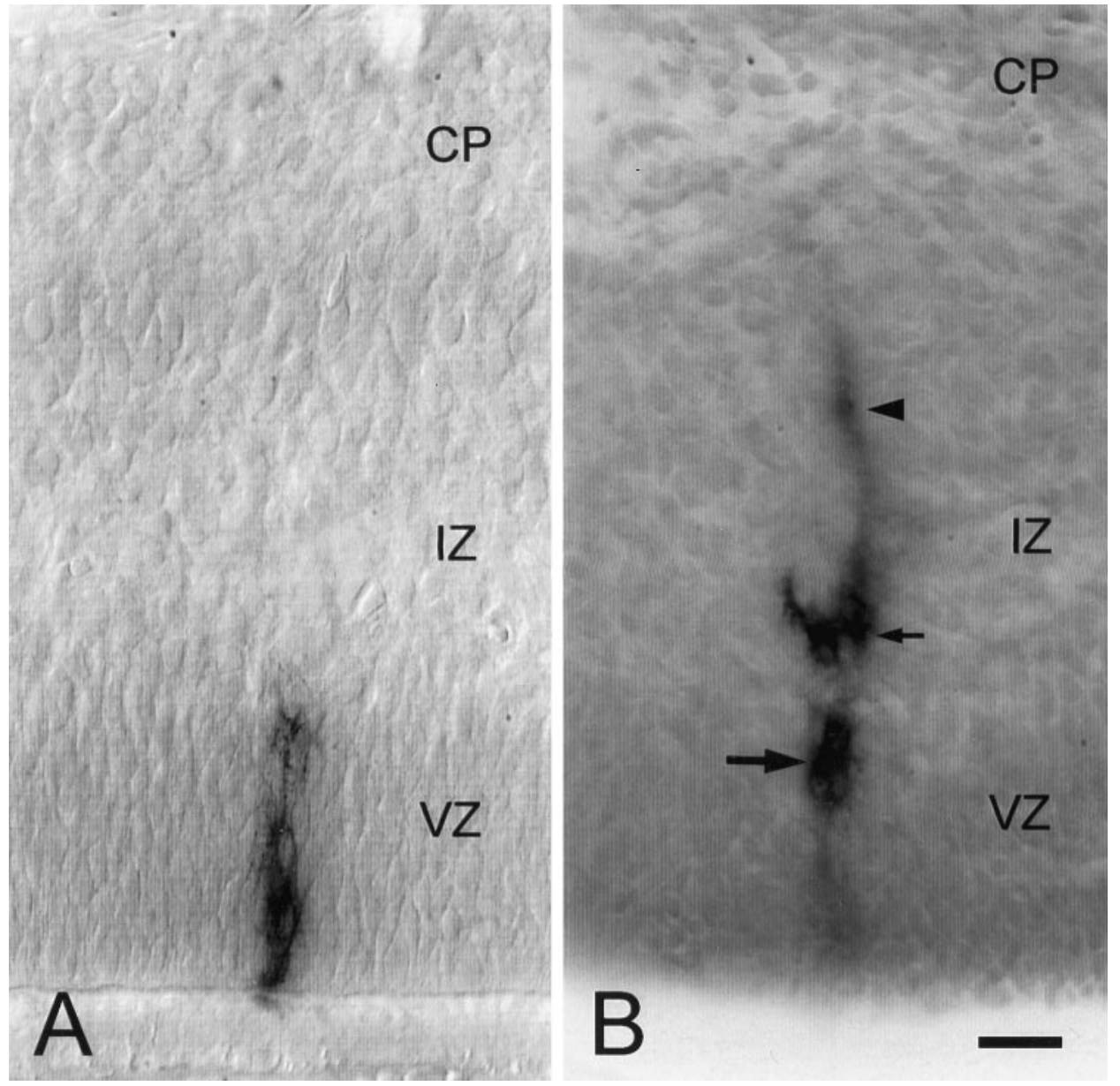

Figure 5. Large clones at E14, $3 \mathrm{~d}$ after injections of DAP retrovirus at E11. $A, \mathrm{P}$ clone containing 8 cells radially aligned in the VZ. Three cells are clustered and located near the VZ/IZ border separated from 5 cells that are tightly clustered and located at the ventricular surface. $B, P Q$ clone containing 5 cells, $3 \mathrm{VZ}$ cells and $2 \mathrm{IZ}$ cells. The $3 \mathrm{VZ}$ cells (larger arrow) are tightly clustered with no discernable intercellular space and are located in the outer one-half of the VZ. The 2 IZ cells (smaller arrow) are located close to each other just above the VZ/IZ border. The arrowhead indicates APstained radial process extending across the IZ. $V$, Lateral ventricle. Scale bar, $20 \mu \mathrm{m}$. tended to be larger than the P clones, ranging from 2 to 24 cells, with a mean size of 8.2 cells/clone. Typically, the PQ clones were easy to recognize and contained VZ, IZ, and CP cells arranged radially (Figs. $2 E, F, 5 B, 6$ ). The radial continuity of these types of clones is emphasized by the radially extending cellular processes that can sometimes be seen to reach the outer one-half of the IZ (as indicated by arrowhead in Fig. 5B).

\section{$P Q$ clones containing one $V Z$ cell}

Only four PQ clones contained one VZ cell. Two of these were two-cell PQ clones, each with one cell in the IZ. The VZ cell of these two clones was located close to the VZ/IZ border, and the IZ cell was located close to the VZ, indicating that it only recently became postproliferative (not illustrated). The remaining two clones both contained three cells; one contained two IZ cells, and one contained two CP cells. We assume that the two CP cells were produced at some earlier cell cycle than the IZ cells to allow enough time for them to migrate through the IZ and to arrive in the CP.

\section{Multicellular PQ clones}

The remaining $44 \mathrm{PQ}$ clones contained two or more VZ cells. The arrangement and tight packing of the VZ cells of these 44 clones was similar to that of the $\mathrm{P}$ clones as described above. Of these 44 clones, 38 clones formed tight clusters that were located across the width of the VZ (Fig. 2E). Ten of these had cells distributed in all developing neocortical strata, i.e., the VZ, IZ, and CP (Fig. 6).
These 10 clones were generally the largest clones, containing from 6 to 24 cells with a mean size of 11.9 cells/clone. An interesting feature of the multicellular PQ clones is that the cells in the VZ and also usually the cells in the more superficial strata were clustered. This was particularly true for the larger PQ clones such as the ones shown in Figures $5 B$ and $6, A$ and $B$. From the proximity of their locations in the IZ and/or in the CP (arrows in Figs. $5 B, 6 A, B)$, these clusters of AP-labeled cells apparently had become postproliferative at the same time and migrated into the IZ at about the same speed. Within a single clone, the spacing of the clusters of VZ, IZ, and CP cells along the radial direction presumably reflects cells that have become postproliferative at different cell cycles. For example, one clone (Fig. 6A) contained a cluster of four IZ cells near the VZ/IZ border (two IZ cells were in the outer one-half of the IZ) and three CP cells that were closely spaced and in radial alignment. Another clone (Fig. 6B) contained three discrete clusters of cells in the IZ and a fourth in the $\mathrm{CP}$, suggesting that cells became postproliferative on four different cell cycles during the proliferative history of this clone. The clone shown in Figure $2 F$ also contained cells in all developing cortical strata, i.e., five VZ cells, two IZ cells, and two CP cells that were aligned radially at strikingly even intervals, again indicating that they were produced at consecutive cell cycles.

\section{Radially arranged VZ cells of the $P Q$ clones}

Radial splitting of VZ cells also occurred in the PQ clones, and the frequency of such radially split clones was slightly higher than 


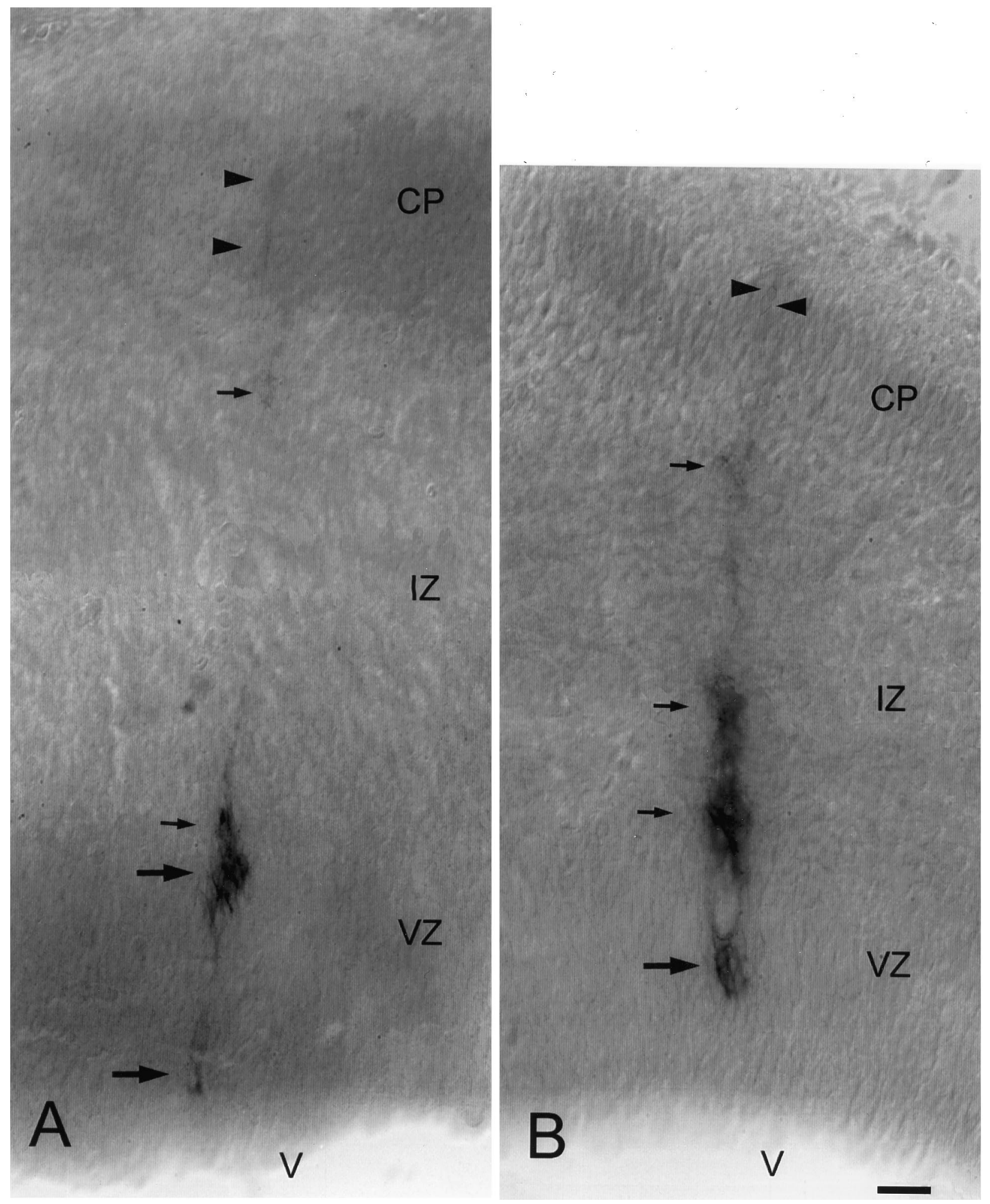

Figure 6. Photomicrographs of the two largest clones found at E14, $3 \mathrm{~d}$ after DAP retrovirus injection at E11. A, The largest clone contained 24 cells. There are $15 \mathrm{VZ}$ cells radially split into two clusters (two larger arrows). The larger cluster contains 13 tightly spaced cells and is located in the outer one-half of the VZ. The smaller cluster contains 2 cells and is located at the ventricular surface. In the IZ (smaller arrows), 4 cells are located near the VZ/IZ border and seem to have recently entered the IZ, and 2 more cells are located at the top of the IZ close to its border with the CP. Two of the three CP cells are faintly stained and are indicated by two arrowheads; the third CP cell is out of the plane of focus of the photomicrograph. $B$, The second largest clone contained 18 cells. There are $6 \mathrm{VZ}$ cells (larger arrow), all located in one tight cluster in the outer one-half of the VZ. The 10 IZ cells (small arrows) are contained in three clusters, indicating perhaps that they had originated during three consecutive cell cycles. One cluster containing 5 cells is located just above the VZ/IZ border and seems to have recently left the VZ. A second cluster containing $3 \mathrm{IZ}$ cells is located in the middle of the IZ. The third cluster with 2 IZ cells is located in the outer one-half of the IZ near the $\mathrm{CP}$. The $2 \mathrm{CP}$ cells (two arrowheads) are faintly stained. $V$, Lateral ventricle. Scale bar, $20 \mu \mathrm{m}$. 
that for the P clones. In 6 of the 48 PQ clones containing more than $2 \mathrm{VZ}$ cells, the $\mathrm{VZ}$ cells were split radially. The largest clone found (Fig. 6A) is an example of a radially split PQ clone. The remaining five clones with radially separated clusters of $\mathrm{VZ}$ cells were also large PQ clones containing six or more cells. Radial separation of clusters of $\mathrm{VZ}$ cells in the PQ clones was sometimes more dispersed than that of clusters of VZ cells in the P clones, although the small sample size cautions against this as a generalization. Also, whereas VZ cells were never found split into more than two clusters in the $\mathrm{P}$ clone, in two PQ clones, VZ cells were found radially split into three clusters (e.g., Fig. $2 F$ ).

\section{Q clones}

Approximately one-third of the clones (86 of 259) were Q clones, i.e., they had no VZ cells (e.g., Fig. $2 C, D$ ). The sizes of the $\mathrm{Q}$ clones ranged from 1 to 12 cells with a mean size of 3.0 cells/clone. Usually, the IZ cells and CP cells of multicellular Q clones were found in clusters. For example, one $\mathrm{Q}$ clone (Fig. $2 C$ ) contained four migrating cells all clustered in the middle of the IZ; no cells were found in the $\mathrm{VZ}$ and $\mathrm{CP}$, although an AP-labeled cellular process extended out to the $\mathrm{CP}$ (arrowhead in Fig. 2C). The $\mathrm{Q}$ clone shown in Figure $2 D$ contained only one cell in the CP; no cells were found in the $\mathrm{VZ}$ or IZ of the underlying cerebral wall or in adjacent sections spanning $300 \mu \mathrm{m}$ in any direction. Note that even the single-cell Q clones in the CP are informative in that the single cell must have been produced in an early cell cycle to allow enough time for migration. However, it cannot be known if this cell was part of a larger clone, the other members of which died or otherwise disappeared or from which it had become laterally displaced.

\section{DISCUSSION}

The main finding of this analysis is that VZ cells of a single clone are not randomly or uniformly distributed in the VZ; rather, clonally related cells occur in tight clusters with all cells in apparent contact and restricted to a narrow portion of the VZ. By what mechanism is the clustering of clonally related cells in the VZ produced and maintained? During the experimental interval used here, essentially $100 \%$ of the $\mathrm{VZ}$ cells are proliferating (Takahashi et al., 1995a); the range of lengths of the cell cycle of proliferating cells in the $\mathrm{VZ}$ is rather narrow, i.e., $< \pm 8 \%$ for the period of this experiment (Cai et al., 1997); and the nuclear locations of the cells in the VZ are well correlated with the phases of the cell cycle (Sauer, 1935; Sauer and Walker, 1959; Takahashi et al., 1993). Therefore, the simplest interpretation of the clustering of clonally related cells is that the cells remain in approximate synchrony as they progress through the cell cycle (Cai et al., 1997). As shown schematically in Figure 7, the two daughter cells from a single mitotic division (Fig. 7, at the onset of Cell cycle 2) will advance from $G_{1}$ through $S, G_{2}$, and $M$ in approximately the same amount of time, and one cell cycle later these same two daughter cells will divide to produce four "cousin" cells (Fig. 7, at the beginning of Cell cycle 3). Moreover, as the cousins progress through the cell cycle in approximate synchrony, they will also tend to remain relatively close to one another. Our data show that this synchrony is maintained during the first one-half of the mouse neuronogenetic period or $5 \pm 1$ cell cycles.

Because each AP-labeled cell in the VZ has divided at least four times since the time of the original retroviral infection, it is not obvious why we found so many small clones (Fig. 1A). There would seem to be four separate and clearly different mechanisms that could affect clone size. First, nonradial movements of cells, i.e., in the plane of the VZ (Fishell et al., 1993), may cause the cells of a single clone to become physically separated (Walsh and Cepko, 1993) or cause the cells of two clones to merge together to form a single clone (Golden et al., 1995). Second, cell death in the VZ (Blascke et al., 1996) would reduce clone size. Third, loss of the label and/or gene expression (Ryder and Cepko, 1993) would also reduce clone size. Fourth, the migration of cells out of the VZ (Caviness et al., 1995; Takahashi et al., 1996) would also reduce clone size. None of these four mechanisms is likely to affect significantly our main finding that clonally related VZ cells occur in tight clusters. This is because we are examining the VZ cells that remain after the mechanisms that might act to reduce (or increase) the number of cells per clone have exerted their influences for five cell cycles. Moreover, this main conclusion is based on the multicellular clones that contain the vast majority of the cells of the VZ (Fig. 1C).

The finding that the VZ cells in $6 \%$ of $\mathrm{P}$ clones and $12.5 \%$ of PQ clones were radially split into two or more clusters would at first seem to contradict the interpretation that clonally related cells remain synchronized in the cell cycle. However, this split phenotype is exactly what would be expected for a clone "caught" either at the $S-G_{2}$ transition or early in $G_{1}$. This is because the descending nuclei in $\mathrm{G}_{2}$ (Fig. 7, cell $b$ in Cell cycle 2) move rapidly from the $S$ phase zone (the outer one-third of the VZ) to the ventricular surface at a speed of about 40 $\mu \mathrm{m} / \mathrm{hr}$, whereas the nuclei in S (Fig. 7, cell $a$ in Cell cycle 2) and the ascending nuclei in $G_{1}$ move at an average speed of only about $10 \mu \mathrm{m} / \mathrm{hr}$ (Takahashi et al., 1993, 1994; Hayes and Nowakowski, unpublished observations). Thus, a "split clone" will be produced when some "advanced" members of a clone enter $G_{2}$ and move rapidly to the ventricular surface, temporarily leaving behind other members of the clone that are still in S. Note that the split clones produced are transient, and as the cells of a clone continue to progress through the cell cycle the cells left behind will also enter $\mathrm{G}_{2}$ and, hence, will "catch up" with their more advanced cousins at the ventricular surface (Fig. 7, end of $\mathrm{G}_{2}$ in Cell cycle 2). Split clones could also be produced in early $\mathrm{G}_{1}$ (Fig. 7, Cell cycle 3) when some cells that have recently left anaphase have been seen to migrate away from the ventricular surface at a relatively faster speed than their "sisters" (Chenn and McConnell, 1995). Thus, it is most probable that split clones are a snapshot of the dynamic situation that occurs at the $S-G_{2}$ transition or during early $G_{1}$. The small proportion of radially split clones is consistent with this interpretation. It should be noted that the split clone phenotype could also be produced by a "double infection," although this happens only rarely (Fields-Berry et al., 1992). However, if double infections occurred, then the descendants formed afterward must have also continued to be synchronized, such that separate clusters were maintained.

From the clustering of clonally related VZ cells and the small variation of their cell cycle length (Cai et al., 1997), it is tempting to speculate that in a clone containing a small number of VZ cells in close apposition, those cells are very closely related as either sisters (i.e., the daughters of a single cell) or as first cousins (i.e., the granddaughters of a single cell). However, this is not necessarily the case. Indeed, the degree of 


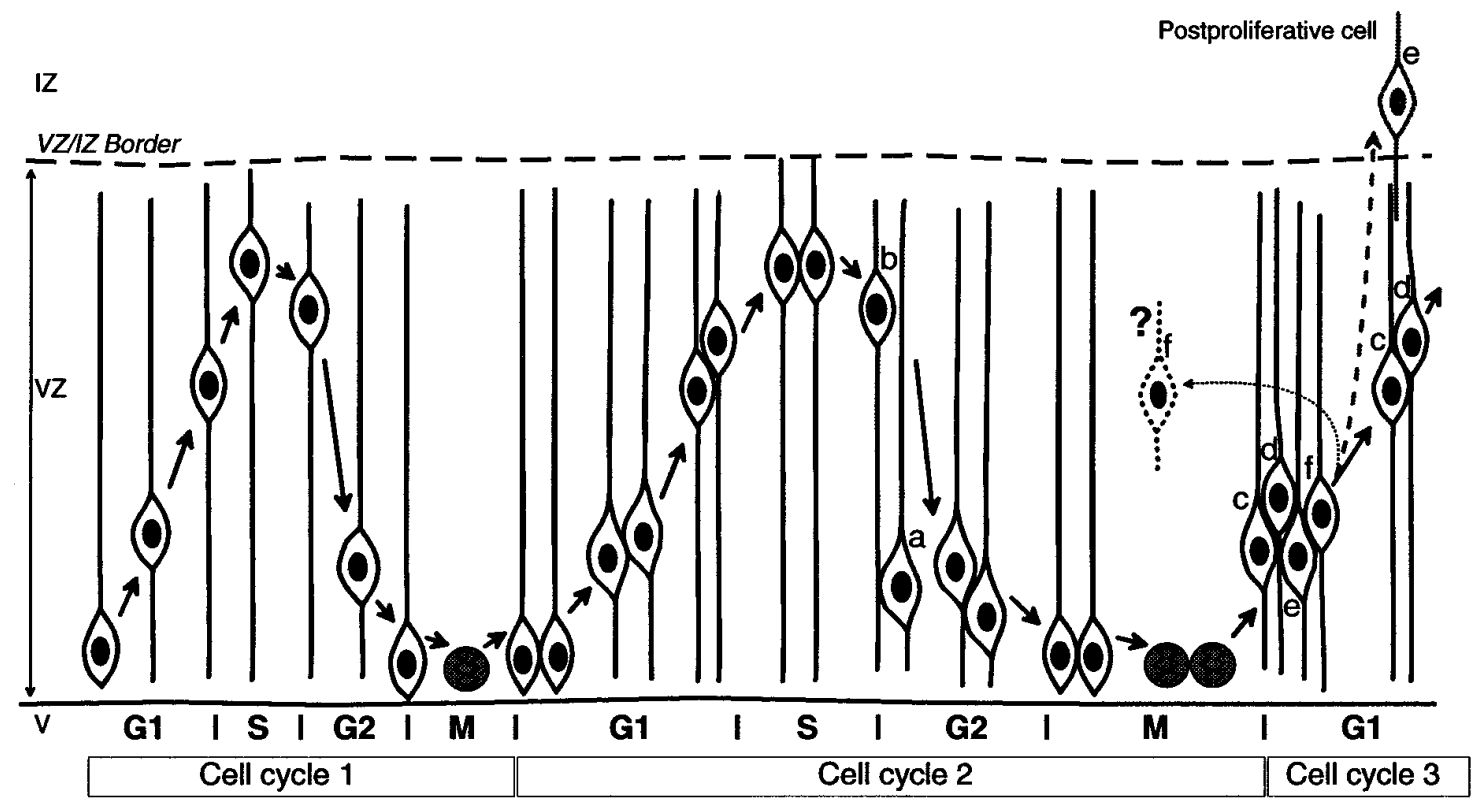

Figure 7. A schematic diagram of interkinetic nuclear migration and the production of mosaicism in the VZ. The to-and-fro movement of a single VZ cell and its progeny and their progression through the cell cycle are depicted over the course of two complete cell cycles and part of a third. At left, the founder cell has just completed $M$ phase and is at the beginning of $\mathrm{G}_{1}$ of Cell cycle 1. During $\mathrm{G}_{1}$, its nucleus ascends to the VZ/IZ border. During S, DNA synthesis occurs in the outer one-half of the VZ. After entry into $\mathrm{G}_{2}$, the nucleus reverses its migratory direction and descends rapidly to the ventricular surface. When Cell cycle 1 is completed, two daughter cells are formed at the beginning of $\mathrm{G}_{1}$ in Cell cycle 2. As these 2 daughter cells repeat the process, they move at approximately the same rate and, hence, maintain their proximity both in the phase of the cell cycle and in their physical location as they progress through Cell cycle 2. A transient "exception" to the maintenance of proximity can occur to produce the split clone phenotype (cells $a$ and $b$ in Cell cycle 2) because the synchrony in the cell cycle is not lock-step but only approximate. A slight difference in cell cycle position at the $\mathrm{S}-\mathrm{G}_{2}$ transition would allow the more advanced of the 2 daughter cells (cell $a$ ) to enter $\mathrm{G}_{2}$ and descend rapidly to the ventricular surface, whereas the slightly retarded daughter would be left behind (cell $b$ ) in $\mathrm{S}$; the 2 daughters would be reunited later in $\mathrm{G}_{2}$. At the end of Cell cycle 2, they divide to form 4 cousin cells in early $\mathrm{G}_{1}$ of Cell cycle 3. During $\mathrm{G}_{1}$, the resultant cluster of cousin nuclei would move to the middle of the ventricular zone as shown at the right of the diagram; however, the fates of the cousins may not be identical. For example, some cells (cells $c$ and $d$ ) might continue to proliferate, and they would maintain synchrony and clustering, whereas others (cell $e$ ) might leave the cell cycle to become postproliferative and migrate into the IZ. Other cells (cell f) might die (for review, see Voyvodic, 1996), lose their AP staining (Golden et al., 1995), or disperse tangentially (Fishell et al., 1993) via an unknown mechanism. As this process continues for additional cell cycles (not illustrated), the resultant cluster of clonally related cells in the VZ forms a clade that contains both siblings and cousins (both near and distant), and its composition, therefore, would be a reflection of its proliferative history.

"kinship" of the VZ cells in a single cluster is not clear simply from the number of cells in the cluster because as many as five cell cycles are likely to have elapsed during the time of this experiment. Thus, two VZ cells could be even more distantly related, i.e., second, third, or even fourth cousins. Given this uncertainty in knowing the degree of kinship, the VZ cells of a single clone constitute a "clade," i.e., a collection of cells derived from a common ancestor but of uncertain relationship. The amount of cell cycle drift that would occur among cells in a clade, i.e., the degree of synchrony or dysynchrony within the clade members as determined by the small variation in cell cycle length (Cai et al., 1997), will clearly be determinable only if methods become available either to measure the cell cycle within a clonally related population or to measure the exact degree of kinship within a clade. Note that it is possible and perhaps even likely that the synchrony and contiguity of cells is maintained by gap junctions, or that clustering, synchrony, and gap junctions are mutually reenforcing. LoTurco and Kriegstein (1991) showed that VZ cells are both dye and electrotonically coupled into groups that seem to span the $\mathrm{VZ}$ and contain 15-90 cells. Gap junctions have been found in vertebrate and invertebrate embryos, where they have been implicated in a variety of processes (Fraser and Bryant, 1985; Guthrie and Gilula, 1989). It would seem that gap junctions among clustered VZ cells may provide a way of transferring information needed for maintaining the physical proximity and synchrony of clone members in the cell cycle and that cells lose these contacts as they prepare to leave the proliferative population. Conversely, cells that lose their junctional attachments to their neighbors may also lose the ability to remain in synchrony and may somehow be "forced" to leave the proliferative population. Regardless of which is causal, the net effect would be to purify the clones into clusters with similar cell cycle lengths (Cai et al., 1993, 1997).

The fact that clonally related cells tend to remain close to one another both physically and in the cell cycle during early neocortical development imparts a mosaic structure to the VZ. This mosaic structure is, in a sense, ephemeral in that it cannot be detected with routine staining methods but requires methods that display clonal relationships. It means that the nuclei of the cells of the VZ are neither randomly nor uniformly distributed but instead are organized into small clades. Each clade remains together as it moves to-and-fro across the width of the $\mathrm{VZ}$ as its constituent cells progress through the cell cycle. It also means that the proliferative history of the $\mathrm{VZ}$ is recorded in its mosaic composition (Fig. 7). One consequence of the mosaic organization of the $\mathrm{VZ}$ is that events controlling and/or disrupting cell proliferation and cell fate may preferentially affect clonally related cells by virtue of their synchrony in the cell cycle (Cai et al., 1997); therefore, they might not act 
uniformly across the surface of a proliferative population. A second consequence of the mosaicism in the VZ might be that output may occur in small "bursts" across the surface of the VZ. Indeed, we found clusters of AP-labeled cells not only in the $\mathrm{VZ}$ but also in the IZ and CP; moreover, the tight spacing of postproliferative cells in the IZ (Figs. $2 F, 5 B, 6 B$ ) and $\mathrm{CP}$ (Fig. 6A) suggests that each cluster is the result of several members of a clone becoming postproliferative simultaneously, i.e., during the same cell cycle. Similar clusters of clonally related cells have been found in the VZ (Kornack and Rakic, 1995), in the IZ of developing striatum (Halliday and Cepko, 1992), in the IZ and CP of developing neocortex (Walsh and Cepko, 1988), and most frequently in mature cortex (Parnavelas et al., 1991; Luskin et al., 1993; Mione et al., 1994; Kornack and Rakic, 1995). Moreover, the synchronously cycling clusters of nuclei of the proliferating cells in the early developing cortex, as revealed by tritiated thymidine autoradiography (Reznikov and van der Kooy, 1995), may also result from clonal clustering. In the mature cortex, the clustering of cells of homogeneous phenotype has been interpreted to mean that the ventricular zone contains separate lineages of progenitor cells that produce different types of neurons, e.g., pyramidal versus nonpyramidal (Parnavelas et al., 1991; Luskin et al., 1993) or GABAergic versus glutamatergic (Mione et al., 1994). However, mosaicism of the VZ also means that cells that share a common lineage also share a common space and, therefore, may have a greater chance of encountering the same environmental cues, perhaps coincident with a signal to leave the proliferative population. In other words, clonally related cells might sometimes share the same fate not because of any intrinsic "lineage potential" but simply because they tend to be adjacent. This needs to be considered carefully when conclusions about lineage versus environmental determinants are inferred from the fates and/or positions of clonally related cells. This is especially significant because the vast majority of the VZ cells $(>90 \%)$ are adjacent to at least one clonally related cell (i.e., reside in a clone with two or more VZ cells), and over $50 \%$ are adjacent to three or more clonally related cells (i.e., reside in a clone with four or more VZ cells; Fig. 1C).

Finally, it should be noted that the principle that the daughters of cells resulting from a single mitotic event tend to remain close to one another both in the cell cycle and in location to produce mosaicism in the proliferative epithelium may have significance beyond the developing neocortex. For example, synchronic clusters of cells have been observed in invertebrate wing disk formation of Drosophila (Milan et al., 1996). This suggests that mosaicism of proliferative epithelia is likely to be found elsewhere in the brain, elsewhere in the developing organism, or even in the adult and may be a universal feature of proliferating systems.

\section{REFERENCES}

Boulder Committee (1970) Embryonic vertebrate central nervous system: revised terminology. Anat Rec 166:257-262.

Cai L, Hayes NL, Nowakowski RS (1993) Comparison of the cumulative S-phase labeling method and the percent labeled mitoses method in the developing cerebral cortex. Soc Neurosci Abstr 19:30.

Cai L, Hayes NL, Nowakowski RS (1995) Synchronized interkinetic nuclear movement during early neuronogenesis in mouse neocortex. Soc Neurosci Abstr 21:286.

Cai L, Hayes NL, Nowakowski RS (1996) Clone size during neocortical development: agreement of experimental and prediction. Soc Neurosci Abstr 22:524.
Cai L, Hayes NL, Nowakowski RS (1997) Local Homogeneity of Cell Cycle Length in Developing Mouse Cortex. J Neurosci 17:2079-2087.

Caviness V, Takahashi T, Nowakowski RS (1995) Numbers, time and neocortical neuronogenesis: a general developmental and evolutionary model. Trends Neurosci 18:379-383.

Cepko CL (1988) Retrovirus vectors and their applications in neurobiology. Neuron 1:345-353.

Cepko CL (1990) Lineage analysis and immortalization of neural cells via retrovirus vectors. In: Neuromethods (Boulton AA, Baker GB, Campagnoni AT, eds), pp 177-219. Clifton, NJ: Humana.

Chenn A, McConnell SK (1995) Cleavage orientation and the asymmetric inheritance of Notch1 immunoreactivity in mammalian neurogenesis. Cell 82:631-641.

Fields-Berry SC, Halliday AL, Cepko CL (1992) A recombinant retrovirus encoding alkaline phosphatase confirms clonal boundary assignment in lineage analysis of murine retina. Proc Natl Acad Sci USA 89:693-697.

Fishell G, Mason CA, Hatten ME (1993) Dispersion of neural progenitors within the germinal zones of the forebrain. Nature 362:636-638.

Fraser SE, Bryant PJ (1985) Patterns of dye coupling in the imaginal wing disk of Drosophila melanogaster. Nature 317:533-536.

Golden JA, Fields-Berry SC, Cepko CL (1995) Construction and characterization of a highly complex retroviral library for lineage analysis. Proc Natl Acad Sci USA 92:5704-5708.

Guthrie SC, Gilula NB (1989) Gap junctional communication and development. Trends Neurosci 11:12-16.

Hajihosseini M, Iavachev L, Price J (1993) Evidence that retroviruses integrate into post-replication host DNA. EMBO J 12:4969-4974.

Halliday AL, Cepko CL (1992) Generation and migration of cells in the developing striatum. Neuron 9:15-26.

Kornack DR, Rakic P (1995) Radial and horizontal deployment of clonally related cells in the primate neocortex: relationship to distinct mitotic lineages. Neuron 15:311-321.

Leblond CP (1964) Classification of cell populations on the basis of their proliferative behavior. Natl Cancer Inst Monogr 14:119-150.

LoTurco JJ, Kriegstein AR (1991) Clusters of coupled neuroblasts in embryonic neocortex. Science 252:563-566.

Luskin MB, Parnavelas JG, Barfield JA (1993) Neurons, astrocytes, and oligodendrocytes of the rat cerebral cortex originate from separate progenitor cells: an ultrastructural analysis of clonally related cells. J Neurosci 13:1730-1750.

Milan M, Campuzano S, Garcia-Bellido A (1996) Cell cycling and patterned cell proliferation in the wing primordium of Drosophila. Proc Natl Acad Sci USA 93:640-645.

Mione MC, Danevic C, Boardman P, Harris B, Parnavelas JG (1994) Lineage analysis reveals neurotransmitter (GABA or glutamate) but not calcium-binding protein homogeneity in clonally related cortical neurons. J Neurosci 14:107-123.

Parnavelas JG, Barfield JA, Franke E, Luskin MB (1991) Separate progenitor cells give rise to pyramidal and nonpyramidal neurons in the rat telencephalon. Cereb Cortex 1:463-468.

Rakic P (1972) Mode of cell migration to the superficial layers of fetal monkey neocortex. J Comp Neurol 145:61-84.

Rakic P (1988) Specification of cerebral cortical areas. Science 241:170-176.

Reid CB, Liang I, Walsh C (1995) Systematic widespread clonal organization in cerebral cortex. Neuron 15:299-310.

Rentrop M, Knapp B, Winter H, Schweizer J (1986) Aminoalkylsilanetreated glass slides as support for in situ hybridization of keratin cDNAs to frozen tissue sections under varying fixation and pretreatment conditions. Histochem J 18:271-276.

Reznikov K, van der Kooy D (1995) Variability and partial synchrony of the cell cycle in the germinal zone of the early embryonic cerebral cortex. J Comp Neurol 360:536-554.

Ryder EF, Cepko CL (1994) Migration patterns of clonally related granule cells and their progenitors in the developing chick cerebellum. Neuron 12:1011-1028.

Sanes JR, Rubenstein JL, Nicolas JF (1986) Use of a recombinant retrovirus to study post-implantation cell lineage in mouse embryos. EMBO J 5:3133-3142.

Sauer FC (1935) Mitosis in the neural tube. J Comp Neurol 62:377-405. Sauer ME, Walker BE (1959) Radioautographic study of interkinetic nuclear migration in the neural tube. Proc Soc Ext Biol 101:557-560.

Sidman RL (1970) Autoradiographic methods and principles for study of 
the nervous system with thymidine- $\mathrm{H}^{3}$. In: Contemporary research methods in neuroanatomy (Nauta WJH, Ebbesson SOE, eds), pp 252274. New York: Springer.

Sidman RL, Miale IL, Feder N (1959) Cell proliferation and migration in the primitive ependymal zone: an autoradiographic study of histogenesis in the nervous system. Exp Neurol 1:322-333.

Takahashi T, Nowakowski RS, Caviness Jr VS (1993) Cell cycle parameters and patterns of nuclear movement in the neocortical proliferative zone of the fetal mouse. J Neurosci 13:820-833.

Takahashi T, Nowakowski RS, Caviness Jr VS (1994) Mode of cell proliferation in the developing mouse neocortex. Proc Natl Acad Sci USA 91:375-379.

Takahashi T, Nowakowski RS, Caviness Jr VS (1995a) The cell cycle of the pseudostratified ventricular epithelium of the embryonic murine cerebral wall. J Neurosci 15:6046-6057.

Takahashi T, Nowakowski RS, Caviness Jr VS (1995b) A computational model of neocortical neuronogenesis. Soc Neurosci Abstr 21:286.

Takahashi T, Nowakowski RS, Caviness Jr VS (1996) The leaving or Q fraction of the murine cerebral proliferative epithelium: a general model of neocortical neuronogenesis. in press.

Voyvodic JT (1996) Cell death in cortical development: How much? Why? So what? Neuron 16:693-696.

Walsh C, Cepko CL (1988) Clonally related cortical cells show several migration patterns. Science 242:1342-1345.

Walsh C, Cepko CL (1993) Clonal dispersion in proliferative layers of developing cerebral cortex. Nature 362:632-635. 